\title{
Theories of Ultrasonic Velocities and their Application in Binary Liquid Mixtures of $N$-Ethylaniline with Some Toluenes (Toluene, $o$-Nitrotoluene and $m$-Nitrotoluene)
}

\author{
B. JHANSI LAKSHMI, G. R. SATYANARAYANA, M. GOWRI SANKAR, \\ D. RAMACHANDRAN and C. RAMBABU*
}

Department of Chemistry, Acharya Nagarjuna University, Nagarjunanagar, Guntur District, Andhra Pradesh, India

rbchintala@gmail.com

Received 31 August 2014 / Accepted 25 September 2014

\begin{abstract}
Ultrasonic velocities and densities of the binary liquid mixtures of $N$-ethyl aniline with different toluenes like toluene, $o$-nitrotoluene and $m$-nitrotoluene have been measured at temperatures 303.15 and $308.15 \mathrm{~K}$ over the entire composition range. Various theories of ultrasonic velocity were applied to experimental values in evaluating the velocities using Nomoto's relation $\left(\mathrm{U}_{\mathrm{NR}}\right)$, Impedence relation $\left(\mathrm{U}_{\mathrm{IR}}\right)$, Ideal mixing relation $\left(\mathrm{U}_{\mathrm{IMR}}\right)$, Jungie's relation $\left(\mathrm{U}_{\mathrm{JR}}\right)$ and Rao's specific velocity relation $\left(U_{R}\right)$. The molecular interaction parameter $(\chi)$ has been evaluated from the values of experimental and theoretical velocities. The variation of this interaction parameter with the composition mixture has been discussed in terms of molecular interactions.
\end{abstract}

Keywords: Ethyl aniline, Theoretical velocities, Ultrasonics, Hydrogen bonding, Interaction parameter

\section{Introduction}

In recent years measurement of ultrasonic investigations find extensive applications in determining the physicochemical behavior of liquid mixtures ${ }^{1-5}$. Several researchers ${ }^{6-9}$ carried out ultrasonic investigations and correlated the experimental results of ultrasonic velocity with the theoretical relations of Nomoto ${ }^{10}$, Van Deal and Vangeel ideal mix relations ${ }^{11}$ impedance relation ${ }^{12}$ Rao's Specific velocity ${ }^{13}$ and Junjie ${ }^{14}$ and interpreted the results in terms of molecular interactions. Ultrasonic study of liquid mixtures, due to its non destructive nature, has been extensively carried out in different branches of science to measure the thermodynamic properties and to predict the nature of molecular interaction between the molecules in a medium. The ultrasonic sound velocity and the thermodynamic parameters derived from it have been widely used to interpret the interactions between unlike molecules in the binary liquid mixtures.Longeman and Correy ${ }^{15}$ discussed sound velocity in a liquid as the sum of bond velocities. Randall ${ }^{16}$ has shown a close agreement between the experimental and theoretical values calculated from the adiabatic compressibility measurements. Auslander et al., ${ }^{17}$, Samal et al., ${ }^{18}$, Aziz et al., ${ }^{19,20}$ and Younglove ${ }^{21}$ showed 
that there is close relation between sound velocity and thermodynamic properties. This investigation presents the application and evaluation of ultrasonic velocity theories like Nomoto's relation, ideal mixing relation, impedance relation, Rao's specific velocity relation and Junjie's relations for the binary mixtures of Ethyl aniline and toluene, $o$-nitrotoluene and $m$-nitro toluene at temperatures 303.15 and $308.15 \mathrm{~K}$,over the entire composition range. An attempt has been made to study the molecular interactions from the deviation values in $\mathrm{U}^{2} / \mathrm{U}^{2}$ imix from unity based on earlier studies ${ }^{22,23}$.

\section{Experimental}

Ethlyaniline (Merck India >0.995 purity) was distilled at low pressure and over freshly activated $0.3 \mathrm{~nm}$ molecular sieves ${ }^{24}$. Other compounds under study as mentioned above (SD Fine Chemicals, India, with purity $>0.995$ ) were purified by methods described in the literature ${ }^{25}$. The purity of the chemicals was verified further by measuring the densities and ultrasonic velocities which are in good agreement with the literature values.

\section{Apparatus and procedure}

The ultrasonic velocity of sound (U) was measured using an ultrasonic interferometer (Mittal Enterprises, New Delhi model -F05) operating at $2 \mathrm{MHz}$. with a precision of $0.8 \mathrm{~m} . \mathrm{s}^{-1}$ and an uncertainty less than $\pm 0.1 \mathrm{~m} . \mathrm{s}^{-1}$. The temperature stability was maintained within $\pm 0.01 \mathrm{~K}$ by circulating water bath around the measuring cell through a pump.

The densities, $\rho$, of pure liquids and their mixtures are determined using a $10^{-5} \mathrm{~m}^{3}$ double-arm pycnometer, and the values from triplicate replication at each temperature are reproducible within $2 \times 10^{-1} \mathrm{~kg} \mathrm{~m}^{3}$ and the uncertainty in the measurement of density is found to be 2 parts in $10^{4}$ parts. The reproducibility in mole fractions was within \pm 0.0002 .

\section{Theory}

Comparison of theoretical values of ultrasonic velocities with those obtained experimentally in binary liquid mixtures is expected to reveal the nature of interaction between component molecules. The measured values of ultrasonic velocity in the binary liquid mixtures were subjected to theoretical prediction and comprehensive theoretical model of prediction has been evaluated. Following are various theories adopted.

\section{Nomotos relation $\left(U_{N R}\right)$}

On assuming the additivity of molar sound velocity(R) and no volume change on mixing, Nomoto established the following relation for the ultrasonic velocity of binary liquid mixtures

$$
\mathrm{R}=\mathrm{M} / \rho \mathrm{U}^{1 / 3}
$$

Where $\mathrm{U}$ and $\rho$ are determined experimentally and $\mathrm{M}$ is the mean molecular weight in a binary liquid mixture

$$
\mathrm{M}=\left(\mathrm{X}_{1} \mathrm{M}_{1}+\mathrm{X}_{2} \mathrm{M}_{2}\right)
$$

Where $\mathrm{M}_{1}$ and $\mathrm{M}_{2}$ are molecular weights of constituent components. Simple manipulation yields the following relation

$$
\mathrm{U}_{\mathrm{NR}}=\left[\left(\mathrm{X}_{1} \mathrm{R}_{1}+\mathrm{X}_{2} \mathrm{R}_{2}\right) /\left(\mathrm{X}_{1} \mathrm{~V}_{1}+\mathrm{X}_{2} \mathrm{~V}_{2}\right)\right]^{3}
$$

\section{Impedance relation $\left(U_{I R}\right)$}

Impedance is the product of ultrasonic velocity $(U)$ and the density $(\rho)$ of a liquid mixture. Hence the impedance relation predicts the ultrasonic velocity of the given mixture by simply using the values of impedance $\left(Z_{i}\right)$ and the density $(\rho)$ values. Impedance relationis given as 


$$
\mathrm{U}_{\mathrm{IR}}=\Sigma \mathrm{X}_{\mathrm{i}} \mathrm{Z}_{\mathrm{i} /} \Sigma \mathrm{X}_{\mathrm{i}} \rho_{\mathrm{i}}
$$

Where $X_{i}$ mole fraction, $\rho_{1}$ is the density of the mixture and $Z_{i}$ is the acoustic impedance

\section{Jungie equation $\left(U_{J}\right)$}

The Junjie equation is given as

$$
\left.\mathrm{U}_{\mathrm{J}}=\left(\mathrm{X}_{1} \mathrm{M}_{1} / \rho_{1}+\mathrm{X}_{2} \mathrm{M}_{2} / \rho_{2}\right) /\left[\left\{\mathrm{X}_{1} \mathrm{M}_{1}+\mathrm{X}_{2} \mathrm{M}_{2}\right\}^{1 / 2}\left\{\mathrm{X}_{1} \mathrm{M}_{1} / \rho_{1} \mathrm{U}_{1}{ }^{2}+\mathrm{X}_{2} \mathrm{M}_{2} / \rho_{2} \mathrm{U}_{2}{ }^{2}\right)\right\}^{1 / 2}\right]
$$

Where $M_{1}, M_{2}$ are molecular weights of constituent components. $\rho_{1}$ and $\rho_{2}$ are the densities of constituent components.

Rao's specific velocity method relation $\left(U_{R}\right)$

$$
\text { Rao's specific velocity method }{ }^{11} U_{R}=\left(\Sigma X_{i} r_{i} d\right)^{3}
$$

Where $\mathrm{Xi}$ is the mole fraction, $\mathrm{U}_{\mathrm{i}}$ the ultrasonic velocity and $\rho_{1 \square}$ the density of the mixture. $r_{i}$ is the Rao's specific sound velocity, which is given by $r_{i}=U i^{1 / 3} / \rho_{i}$ and $Z_{i}$ is the acoustic impedance.

\section{Ideal mixing relation $\left(U_{\text {imix }}\right)$}

Van Deal and Vangeel (1969) suggested the following relation for the velocity of sound

$$
1 /\left(\mathrm{X}_{1} \mathrm{M}_{1}+\mathrm{X}_{2} \mathrm{M}_{2}\right)^{*} 1 / \mathrm{U}^{2}{ }_{\text {imix }}=\mathrm{X}_{1} / \mathrm{M}_{1} \mathrm{U}_{1}{ }^{2}+\mathrm{X}_{2} / \mathrm{M}_{2} \mathrm{U}_{2}{ }^{2}
$$

Where $U_{\text {imix }}$ is the ideal mixing ultrasonic velocity in liquid mixture and $U_{1}$ and $U_{2}$ are the velocities of the individual components. The degree of molecular interaction given as interaction parameter $(\chi)$

$$
\begin{aligned}
& =\left(\mathrm{U}^{2} \exp / \mathrm{U}^{2}{ }_{\text {imix }}\right)^{-1} \\
\text { Percentage deviation } & =(\Delta \mathrm{U} / \mathrm{U}) \%=\left[\left(\mathrm{U}_{\exp }-\mathrm{U}_{\text {theoritical }} / \mathrm{U}_{\exp }\right]^{*} 100\right.
\end{aligned}
$$

\section{Results and Discussion}

Amines are derivatives of ammonia, wherein one or more hydrogen atoms have been replaced by a substituent such as an alkyl or aryl group. The aromatic ring decreases the alkalinity of the amine, depending on its substituents, while the presence of an amine group strongly increases the reactivity of the aromatic ring, due to an electron-donating effect.

When a methyl group is introduced into the aromatic ring, it causes to change in the $\pi$ - electron density around the aromatic ring ${ }^{26}$ because of positive mesomeric and positive electromeric effects. (+T effect $>-\mathrm{I}$ effect). Further, substitution of $-\mathrm{NO}_{2}$ group at ortho and meta positions of benzene molecule increase the distance of closest approach of the $N$-ethyl aniline molecule resulting decrease in interaction between component molecules. Toluene is more reactive or activated with respect to benzene. It is a fact that the effect of substituents on a benzene ring have on both the rate and orientation of electrophilic aromatic substitution reactions. These effects are a combination of resonance and inductive effects. The substituent $-\mathrm{NO}_{2}$ is an electron withdrawing group that removes electron density from the $\pi$ system making it less nucleophilic. Besides the electronic effects, influences from steric effects are also to be considered.The effect on the $\pi$-electron density due to methyl group is relatively small, which tends to decrease the magnitude of $\mathrm{V}^{\mathrm{E}}$.The difference in shapes of molecules with the addition of methyl and - $\mathrm{NO}_{2}$ groups also leads to different alignments in the liquid mixtures. Further, the electron donor-acceptor interactions tend to decrease with additional functional groups. 
<smiles>CCNc1ccccc1</smiles>

N-Ethylaniline<smiles>Cc1ccccc1</smiles>

Toluene<smiles>Cc1ccccc1[N+](=O)[O-]</smiles>

o-Nitro toluene<smiles>Cc1cccc([N+](=O)[O-])c1</smiles>

m-Nitro toluene

With this above explanation in understanding the molecular interactions, we further extended our study in testing the validity of various theoretical approaches of ultrasonic velocity for liquids in the aforementioned binary systems by comparing theoretical sound speeds with those experimentally determined in the temperature range 303.15-318.15 K. The experimental values of sound speed for the systems along with theoretical values and percentage deviations for Nomoto's Relation $\left(\mathrm{U}_{\mathrm{NR}}\right)$, Vandeal Vangael Ideal Mixing Relation $\left(\mathrm{U}_{\mathrm{IMR}}\right)$, Impedance Relation $\left(U_{I R}\right)$, Rao's specific velocity method $\left(U_{R}\right)$ and Junjie's relation $\left(U_{J}\right)$ are compared for all the five binaries. It is assumed that all the molecules are spherical in shape, which is not true every time. In Nomoto's theory, it is supposed that the volume does not change on mixing. Therefore, no interaction between the components of liquid mixtures has been taken into account. The assumption for the formation of ideal mixing relation is that, the ratio of specific heats of ideal mixtures and the volumes are also equal. Again, no molecular interaction is taken into account. Similarly, as per the assumption for the Collision Factor theory, the molecules are treated as real non- elastic substances, which is not really the case. But on mixing two liquids, the interaction between the molecules of the two liquids takes place because of presence of various types of forces such as dispersion forces, charge transfer, hydrogen bonding, dipole dipole and dipole - induced dipole interactions. Thus, the observed deviation of theoretical values of velocity from the experimental values shows that the molecular interaction is taking place between the unlike molecules in the liquid mixture. It can be seen from Tables 1-3 that the theoretical values of ultrasonic velocity computed by various theories show deviations from experimental values. In general the predictive ability of various ultrasonic theories depends upon the strength of interactions that exist in a binary system. In case of strong interactions existing between the molecules of the mixtures there is much deviation in theoretical prediction of velocity than the molecules of the mixture where less interaction is observed.

Data reveal that the sound speed computed from impedance relation, $\mathrm{U}_{\mathrm{imr}}$ exhibit more satisfactory agreement with the experimental values in the temperature range $303.15 \mathrm{~K}$ $318.15 \mathrm{~K}$ than other approaches in the binary systems $N$-ethyl aniline + toluene.

Table 1 show that in the system of $N$-ethylaniline + toluenethere is good agreement between experimental and theoretical values calculated by impedance and Nomoto relations. Here Nomoto relation provides the best result than theImpedance relation at all the temperatures. However, higher deviations are observed in Rao's specific and slight variations in Junjie's theories. Ethyl aniline+ $o$-nitro toluene system, as described in Table 2, there is good agreement between experimental and theoretical values in Nomoto relation followed by impedance relations where as higher deviations are observed in VanDael ideal mixing relation, Rao's specific velocity method and Junjie's relation. Ethyl aniline and mnitro toluene, Ethyl aniline+ $o$-nitro toluene system, as described in Table 3 showed good agreement between experimental and theoretical values calculated by Rao's specific velocity method and impedance relation. Here Rao's specific velocity method provides the best result than the result of impedance relation at all temperatures. However, higher deviations are observed in Nomoto's relation, Van Dael ideal mixing relation and Junjie's theory. Table 4 shows the $\mathrm{U}^{2}{ }_{\exp } / \mathrm{U}^{2}{ }_{\text {imx }}$ values from the the derived velocity values for these systems. 
The percentage deviations of the ultrasonic velocity are both negative and positive. Such deviations indicate the non-ideal behavior of liquid mixtures. The ratio $\mathrm{U}^{2}{ }_{\exp } / \mathrm{U}^{2}{ }_{\text {imx }}$ is used as an important tool to measure the non-ideality in the mixtures, especially in these cases where the properties other than sound velocity are not known .A perusal of values indicate small deviations from ideality, which may be due to the existence of weak tendency for the formation of association in liquid mixtures.

Looking into the behavior of all three binary mixtures, it can be understood that, positive deviation in velocity are attributed to the molecular associations, complex formations, whereas negative deviations indicate molecular dissociations of an associated species by the addition of solvent. In our investigation, all systems showed positive deviations with lower magnitude, indicating weak interactions. Maximum positive values for $\mathrm{U}^{2}{ }_{\text {exp }} / \mathrm{U}^{2}$ imix are observed in case of Ethyl aniline+ $m$-nitro toluene $(1.164$ at $308.15 \mathrm{~K})$, than Ethyl aniline+ $o$-nitro toluene (1.133 at $303.15 \mathrm{~K}$ ) at nearly equimolar composition at all measured temperatures due to specific interactions/complex formations between unlike molecules through hydrogen bonding. Ethyl aniline+toluene systems also showed decreasing values for $\mathrm{U}^{2}{ }_{\text {exp }} / \mathrm{U}^{2}$ imix , as revealed from Table 4. The $\mathrm{U}^{2}{ }_{\text {exp }} / \mathrm{U}^{2}$ imix values of all five binaries have been shown in table 4 .

Table 1-3. Values of experimental ultrasonic velocities and evaluated theoretical velocities along with percentage deviations and interaction parameters for the studied systems at temperatures $303.15 \mathrm{~K}-308.15 \mathrm{~K}$

Table 1. $N$-Ethylaniline +Toluene

$303.15 \mathrm{~K}$

\begin{tabular}{|c|c|c|c|c|c|c|c|c|c|c|c|c|}
\hline $\mathrm{x} 1$ & Uexp & Unomoto & Uimx & Uir & Urao & $\mathrm{Uj}$ & \%Unom & \%Uimx & \%Uir & $\% U r$ & $\% \mathrm{Uj}$ & $\alpha$ \\
\hline 0 & 1278 & 1278 & 1278 & 1278 & 1278 & 1278 & 0 & 0 & 0 & 0 & 0 & 0 \\
\hline 0.0612 & 1298.3 & 1292.5 & 1295.3 & 1292.7 & 1337.4 & 1288.6 & -0.446 & -0.235 & -0.434 & 3.015 & -0.745 & 0.005 \\
\hline 0.1325 & 1318.7 & 1309.2 & 1316.3 & 1309.5 & 1358 & 1301.4 & -0.72 & -0.185 & -0.696 & 2.981 & -1.312 & 0.004 \\
\hline 0.1921 & 1334.3 & 1323 & 1334.6 & 1323.4 & 1373.6 & 1312.4 & -0.848 & 0.025 & -0.817 & 2.943 & -1.642 & -0.001 \\
\hline 0.2468 & 1348.3 & 1335.5 & 1352.2 & 1336 & 1386.8 & 1322.8 & -0.949 & 0.289 & -0.914 & 2.854 & -1.895 & -0.006 \\
\hline 0.3319 & 1368 & 1354.7 & 1380.9 & 1355.3 & 1405.5 & 1339.4 & -0.972 & 0.946 & & 2.745 & -2.091 & -0.019 \\
\hline 0.4269 & 1389.3 & 1375.8 & & 1376.4 & & 1358.7 & -0.973 & 1.871 & & 2.526 & -2.2 & -0.036 \\
\hline 0.4858 & 1402.1 & 1388.7 & 1437.9 & 138 & & 1371.2 & -0.959 & 2.556 & & 2.355 & -2.207 & -0.049 \\
\hline 0.5695 & 1420.3 & 1406.7 & 1472.1 & 1407.3 & 1449.2 & 1389.4 & -0.957 & 3.644 & -0.917 & 2.031 & -2.176 & -0.069 \\
\hline 412 & 35.5 & 1421.9 & 15 & 1422.5 & 1460 & 1405.6 & -0.9 & 4.723 & -0.908 & 1.709 & -2.085 & -0.088 \\
\hline 0.7082 & 9.4 & & & 6.5 & 9.3 & 1421.2 & -0.924 & 5.863 & -0.893 & 1.374 & -1.946 & 108 \\
\hline 0.7729 & 2.4 & 144 & & 9.8 & 7.3 & 1436.7 & -0.888 & 7.104 & -0.863 & 1.016 & -1.755 & 128 \\
\hline 0.8415 & 4.9 & 3.4 & 2.4 & 3.7 & 4.5 & 1453.7 & -0.776 & 8.644 & -0.758 & 0.648 & -1.435 & 53 \\
\hline 0.9069 & 1485.4 & 1476.7 & 1639.3 & 1476.8 & 1490 & 1470.5 & -0.588 & 10.358 & -0.577 & 0.311 & -1.006 & -0.179 \\
\hline 1 & 1495.2 & 1495.2 & 1696.4 & 1495.2 & 1495.2 & 1495.2 & 0 & 13.456 & 0 & 0 & 0 & -0.223 \\
\hline \multicolumn{13}{|c|}{ 308.15 K } \\
\hline 0 & 1258.5 & 1258.5 & 1258 & 1258.5 & 1258.5 & 1258.5 & -1.526 & -1.565 & -1.525 & -1.526 & -1.526 & 0.032 \\
\hline 0.0612 & 1278.3 & 1273.3 & 1264.2 & 1273.5 & 1280.8 & 1269.3 & -1.499 & -2.203 & -1.48 & .9 & -1.811 & 0.046 \\
\hline 0.1325 & 1299 & 1290.3 & 1272.3 & 1290.8 & 1304.5 & 1282.2 & -1.465 & -2.842 & -1. & -0.3 & -2.086 & 0.059 \\
\hline & 1314.8 & & & 1305 & & 129 & & & & & & 69 \\
\hline & & & & 1317.8 & 8.2 & 1303 & -1.408 & -3.635 & & & & 977 \\
\hline 319 & & 36.8 & 1300 & 7.6 & 1360.6 & 1320.8 & -1.363 & -4.039 & -1.305 & 0.395 & 42 & 86 \\
\hline 269 & 1370.8 & 8.3 & 1317.2 & 1359.2 & 1383.7 & 1340.5 & -1.312 & -4.3 & -1.25 & 0.53 & -2.604 & 0.092 \\
\hline 0.4858 & 1384 & 71.5 & 1328.7 & 1372.3 & 1397 & 1353.2 & -1.279 & -4.358 & -1.218 & 0.56 & -2.595 & 0.093 \\
\hline 0.5695 & 1402.4 & 1389.9 & 1346.7 & 1390.8 & 1415 & 1371.8 & -1.231 & -4.301 & -1.174 & 0.546 & -2.518 & 0.092 \\
\hline 0.6412 & 1418.1 & 1405.5 & 1363.9 & 1406.3 & 1429.3 & 1388.4 & -1.189 & -4.1 & -1.137 & 0.483 & -2.395 & 0.088 \\
\hline 0.7082 & 1432.1 & 1419.9 & 1381.6 & 1420.6 & 1441.8 & 1404.4 & -1.15 & -3.821 & -1.105 & 0.369 & -2.232 & 0.081 \\
\hline 0.7729 & 1444.8 & 1433.7 & 1400.2 & 1434.2 & 1452.8 & 1420.4 & -1.112 & -3.421 & -1.074 & 0.208 & -2.03 & 0.072 \\
\hline 0.8415 & 1457.4 & 1448 & 1421.8 & 1448.5 & 1463.2 & 1437.8 & -1.071 & -2.862 & -1.044 & -0.034 & -1.769 & 0.06 \\
\hline 0.9069 & 1468.1 & 1461.6 & 1444.5 & 1461.8 & 1471.6 & 1455.1 & -1.032 & -2.19 & -1.015 & -0.35 & -1.474 & 0.045 \\
\hline 1 & 1480.6 & 1480.6 & 1480.6 & 1480.6 & 1480.6 & 1480.6 & -0.977 & -0.977 & -0.976 & -0.977 & -0.977 & 0.02 \\
\hline
\end{tabular}


Table 2. $N$-Ethylaniline $+o$-Nitrotoluene

303.15 K

\begin{tabular}{|c|c|c|c|c|c|c|c|c|c|c|c|c|}
\hline $\mathrm{x} 1$ & $\mathrm{u} / \exp$ & Unomoto & Uimx & Uir & Urao & $\mathrm{Uj}$ & \%Unom & \%Uimx & \%Uir & \%Ur & $\% U j$ & $\alpha$ \\
\hline 0 & 2103 & 2103 & 2103 & 2103 & 2013 & 2103 & 0 & 0 & 0 & -4.28 & 0 & 0 \\
\hline 0.0745 & 2063.2 & 2049.7 & 2021 & 2065.1 & 1969.1 & 2009.5 & -0.654 & -2.472 & 0.092 & -4.562 & -2.604 & 0.051 \\
\hline 0.1642 & 2015.5 & 1987.4 & 1935.6 & 2018.1 & 1917.8 & 1916.1 & -1.392 & -4.885 & 0.13 & -4.846 & -4.934 & 0.105 \\
\hline 0.2205 & 1985.5 & 1949.4 & 1888.2 & 1987.9 & 1886.4 & 1865.8 & -1.818 & -6.13 & 0.119 & -4.991 & -6.03 & 0.135 \\
\hline 0.2925 & 1945.6 & 1901.9 & 1833.2 & 1948.3 & 1847 & 1809 & -2.248 & -7.393 & 0.137 & -5.07 & -7.022 & 0.166 \\
\hline 0.3705 & 1902.5 & 1851.8 & 1779.9 & 1904.2 & 1805 & 1755.3 & -2.666 & -8.485 & 0.087 & -5.123 & -7.737 & 0.194 \\
\hline 0.4325 & 1865.7 & 1813 & 1741.4 & 1868.2 & 1772.2 & 1717.5 & -2.827 & -9.044 & 0.132 & -5.01 & -7.944 & 0.209 \\
\hline 0.5124 & 1816.2 & 1764.2 & 1696.1 & 1820.5 & 1730.6 & 1674.1 & -2.863 & -9.437 & 0.239 & -4.711 & -7.826 & 0.219 \\
\hline 0.5825 & 1771.5 & 1722.6 & 1660 & 1777.6 & 1694.8 & 1640.2 & -2.762 & -9.524 & 0.342 & -4.332 & -7.413 & 0.222 \\
\hline 0.6612 & 1720.2 & 1677.1 & 1622.9 & 1727.9 & 1655.2 & 1606.1 & -2.507 & -9.357 & 0.446 & -3.778 & -6.633 & 0.217 \\
\hline 0.7402 & 1667.7 & 1632.7 & 1588.9 & 1676.4 & 1616.3 & 1575.5 & -2.101 & -8.922 & 0.524 & -3.081 & -5.527 & 0.206 \\
\hline 0.8145 & 1618.2 & 1592 & 1559.5 & 1626.5 & 1580.5 & 1549.7 & -1.616 & -8.311 & 0.516 & -2.329 & -4.235 & 0.189 \\
\hline 0.8852 & 1570.2 & 1554.4 & 1533.5 & 1577.7 & 1547.3 & 1527.3 & -1.008 & -7.503 & 0.476 & -1.458 & -2.729 & 0.169 \\
\hline 0.9124 & 1552.9 & 1540.1 & 1524 & 1558.5 & 1534.7 & 1519.3 & -0.822 & -7.215 & 0.36 & -1.17 & -2.164 & 0.162 \\
\hline 1 & 1495.2 & 1495.2 & 1495.2 & 1495.2 & 1495.2 & 1495.2 & 0 & -5.999 & 0 & 0 & 0 & 0.132 \\
\hline \multicolumn{13}{|l|}{$308.15 \mathrm{~K}$} \\
\hline 0 & 2093 & 2093 & 2093 & 2093 & 2093 & 2093 & 0.0001 & 0 & 0 & -0.0001 & 0 & 0 \\
\hline 0.0745 & 2063.1 & 2039.2 & 2009.8 & 2054.9 & 2040.1 & 1997.9 & -1.1607 & -2.583 & -0.399 & -1.1155 & -3.1596 & 0.0537 \\
\hline 0.1642 & 2016.5 & 1976.3 & 1923.4 & 2007.6 & 1978.1 & 1903.2 & -1.9946 & -4.6145 & -0.4415 & -1.9026 & -5.6163 & 0.0991 \\
\hline 0.2205 & 1988.5 & 1937.9 & 1875.5 & 1977.1 & 1940.2 & 1852.4 & -2.5457 & -5.6817 & -0.5714 & -2.4284 & -6.8431 & 0.1241 \\
\hline 0.2925 & 1946.7 & 1889.9 & 1820.1 & 1937.3 & 1892.7 & 1795.1 & -2.9164 & -6.5045 & -0.4847 & -2.7744 & -7.786 & 0.144 \\
\hline 0.3705 & 1900.4 & 1839.4 & 1766.3 & 1892.9 & 1842.5 & 1741.1 & -3.2095 & -7.0557 & -0.3971 & -3.0474 & -8.3829 & 0.1576 \\
\hline 0.4325 & 1861.4 & 1800.3 & 1727.6 & 1856.6 & 1803.5 & 1703.1 & -3.2837 & -7.1898 & -0.257 & -3.1116 & -8.5056 & 0.1609 \\
\hline 0.5124 & 1809.3 & 1751.2 & 1682.1 & 1808.6 & 1754.3 & 1659.5 & -3.2137 & -7.0299 & -0.0364 & -3.0379 & -8.2803 & 0.1569 \\
\hline 0.5825 & 1762.8 & 1709.2 & 1645.8 & 1765.3 & 1712.2 & 1625.5 & -3.039 & -6.6355 & 0.143 & -2.8676 & -7.7889 & 0.1472 \\
\hline 0.6612 & 1710.4 & 1663.4 & 1608.6 & 1715.3 & 1666.2 & 1591.4 & -2.7463 & -5.9526 & 0.2837 & -2.5861 & -6.9592 & 0.1306 \\
\hline 0.7402 & 1657.1 & 1618.8 & 1574.4 & 1663.4 & 1621.1 & 1560.8 & -2.3137 & -4.9877 & 0.38 & -2.1747 & -5.8114 & 0.1077 \\
\hline 0.8145 & 1606.4 & 1577.9 & 1545 & 1613.1 & 1579.7 & 1535 & -1.7737 & -3.8252 & 0.4172 & -1.6632 & -4.4473 & 0.0811 \\
\hline 0.8852 & 1559.1 & 1540 & 1519 & 1563.8 & 1541.2 & 1512.7 & -1.2221 & -2.5738 & 0.3017 & -1.1471 & -2.9782 & 0.0535 \\
\hline 0.9124 & 1540.4 & 1525.7 & 1509.5 & 1544.5 & 1526.6 & 1504.6 & -0.9519 & -2.0077 & 0.263 & -0.8935 & -2.322 & 0.0414 \\
\hline 1 & 1480.6 & 1480.6 & 1480.6 & 1480.6 & 1480.6 & 1480.6 & 0 & 0 & 0.0004 & 0.0001 & 0.0002 & 0 \\
\hline
\end{tabular}


Table 3. $N$-Ethylaniline $+m$-Nitrotoluene

303.15 K

\begin{tabular}{|c|c|c|c|c|c|c|c|c|c|c|c|c|}
\hline $\mathrm{x} 1$ & $\mathrm{u} / \exp$ & Unomot & Uimx & Uir & Urao & $\mathrm{Uj}$ & \%Uno & & & $\% U r$ & $\% U j$ & $\alpha$ \\
\hline 0 & 2087 & 2087 & 2087 & 2087 & 2087 & 2087 & 0 & 0 & 0 & 0 & 0 & 0 \\
\hline 0.0805 & 2043.3 & 2031.4 & 2002 & 2046.9 & 2030 & 1991.1 & -0.584 & -2.021 & 0.176 & -0.651 & -2.555 & 0.042 \\
\hline 0.1568 & 2001 & 1980.1 & 1931.7 & 2007.9 & 1978.4 & 1914.6 & -1.047 & -3.462 & 0.343 & -1.127 & -4.319 & .073 \\
\hline 0.2258 & 1962.4 & 1934.8 & 1875.2 & 1971.6 & 933.5 & 1854.8 & -1.405 & -4.443 & 0.471 & -1.472 & -5.481 & 0.095 \\
\hline 0.2874 & 1927.9 & 1895.4 & 1829.5 & 1938.6 & 1894.4 & 1807.7 & -1.688 & -5.102 & 0.553 & -1.735 & -6.234 & 0.11 \\
\hline 0.3625 & & & 1779.1 & 1897.2 & 1848 & 1756.8 & -1.958 & -5.635 & 0.632 & -1.978 & -6.816 & .123 \\
\hline 0.4405 & 1840.3 & 1800.9 & 1731.8 & 1853.1 & 1800.9 & 1710.3 & -2.142 & -5.895 & 0.695 & -2.143 & -7.066 & 0.129 \\
\hline 0.5101 & 1799.8 & 175 & 93.5 & 1812.6 & 1759.6 & 1673.3 & -2.236 & -5.907 & 0.712 & -2.234 & -7.026 & \\
\hline 0.5825 & 1756.7 & 1717.6 & 1656.9 & 1769.4 & 1717.6 & 1638.9 & -2.225 & -5.679 & 0.723 & -2.228 & -6.708 & 0.124 \\
\hline 635 & 1707.5 & & 1619.6 & 1719.6 & 671.6 & 1604.3 & -2.083 & -5.148 & 0.71 & -2.105 & -6.042 & \\
\hline 0.7321 & 1665.2 & 1634.2 & 1590.5 & 1676.3 & 1633.6 & 1578 & -1.86 & -4.484 & 0.664 & -1.897 & -5.238 & 0.096 \\
\hline 0.7956 & 1625.5 & 160 & 1565.5 & 1635.1 & 1599.4 & 1555.7 & -1.562 & -3.692 & 0.588 & -1.608 & -4.295 & 0.078 \\
\hline 0.8612 & & 156 & 1541.3 & 1591.4 & 564.9 & 1534.5 & -1.159 & -2.694 & 0.468 & -1.204 & -3.123 & 0.056 \\
\hline 0.9212 & 1545.9 & 1534.8 & 1520.6 & 1550.5 & 1534.5 & 1516.7 & -0.719 & -1.637 & 0.297 & -0.739 & -1.89 & 0.034 \\
\hline 1 & & & 1495.2 & 1495.2 & 1496.2 & 1495.2 & 0 & 0 & 0 & 0.067 & 0 & 0 \\
\hline \multicolumn{13}{|c|}{308.15 K } \\
\hline 0 & 2080 & 2080 & 2080 & 2080 & 2080 & 2080 & -0.335 & -0.35 & & -0.335 & -0.335 & 0.007 \\
\hline 0.0805 & 2041.2 & 202 & 1993.2 & 2039.4 & 2022.8 & 1982.1 & -1.142 & -2.624 & -0.367 & -1.177 & -3.167 & 55 \\
\hline 1568 & 2003.8 & 1971.5 & 1921.6 & 1999.9 & 1970.8 & 1904.2 & -1.811 & -4.295 & -0.399 & -1.847 & -5.163 & 0.092 \\
\hline 2258 & 1968.9 & 192 & 1864.2 & 1963.2 & .2 & 1843.5 & -2.334 & -5.449 & -0.429 & -2.355 & -6.498 & 119 \\
\hline 0.2874 & 1935.9 & 1885.6 & 1817.9 & 1929.7 & 1885.5 & 1795.7 & -2.732 & -6.226 & -0.458 & -2.739 & -7.367 & 0.137 \\
\hline 0.3625 & 1893.4 & & 1766.7 & 1887.8 & 1838.2 & 1744.2 & -3.122 & -6.879 & -0.496 & -3.111 & -8.065 & 153 \\
\hline 0.4405 & 1846.7 & 1789.9 & 1718.9 & 1843.1 & 1790.2 & 1697.2 & -3.412 & -7.24 & -0.538 & -3.392 & -8.413 & 0.162 \\
\hline 0.5101 & 1803.2 & & 1680.2 & 1802.1 & 1748.3 & 1659.9 & -3.565 & -7.305 & -0.579 & -3.548 & -8.425 & 0.164 \\
\hline 0.5825 & 1757.1 & 1705.5 & 1643.4 & 1758.4 & 1705.7 & 1625.1 & -3.609 & -7.124 & -0.625 & -3.603 & -8.154 & 0.159 \\
\hline 0.6635 & 1704.5 & 1659.3 & 1605.7 & 1707.9 & 1659 & 1590.3 & -3.508 & -6.625 & -0.68 & -3.525 & -7.518 & 0.147 \\
\hline 0.7321 & 1658.9 & 1621.1 & 1576.4 & 1664 & 1620.5 & 1563.8 & -3.287 & -5.955 & -0.731 & -3.324 & -6.707 & 0.131 \\
\hline 0.7956 & 1616.8 & 1586.6 & 1551.2 & 1622.3 & 1585.8 & 1541.4 & -2.962 & -5.127 & -0.782 & -3.015 & -5.729 & 0.111 \\
\hline 0.8612 & 1573.7 & 1551.8 & 1526.9 & 1578.1 & 1550.8 & 1520.1 & -2.49 & -4.051 & -0.839 & -2.553 & -4.48 & 0.086 \\
\hline 0.9212 & 1534.5 & 1520.6 & 1506.1 & 1536.6 & 1519.8 & 1502.2 & -1.928 & -2.862 & -0.895 & -1.98 & -3.115 & 0.06 \\
\hline 1 & 1480.6 & 1480.6 & 1480.6 & 1480.6 & 1480.6 & 1480.6 & -0.977 & -0.977 & -0.976 & -0.977 & -0.976 & 0.02 \\
\hline
\end{tabular}

Table 4. $\mathrm{U}^{2} / \mathrm{U}^{2}{ }_{\text {imix }}$ values for all three systems studied at temperatures $303.15 \mathrm{~K}$ and $308.15 \mathrm{~K}$

\begin{tabular}{ccccccccc}
\hline \multicolumn{2}{c}{ EA+ toluene } & \multicolumn{4}{c}{ EA+o-Nitrotoluene } & \multicolumn{3}{c}{ EA+ m-Nitrotoluene } \\
\hline $\mathrm{x} 1$ & $303.15 \mathrm{~K}$ & $308.15 \mathrm{~K}$ & $\mathrm{x} 1$ & $303.15 \mathrm{~K}$ & $308.15 \mathrm{~K}$ & $\mathrm{x} 1$ & $303.15 \mathrm{~K}$ & $308.15 \mathrm{~K}$ \\
\hline 0 & 1 & 1 & 0 & 1 & 1 & 0 & 1 & 1 \\
0.0612 & 1.0096 & 1.0122 & 0.0745 & 1.018 & 1.027 & 0.0805 & 1.042 & 1.055 \\
0.1325 & 1.0199 & 1.0278 & 0.1642 & 1.049 & 1.064 & 0.1568 & 1.073 & 1.092 \\
0.1921 & 1.0266 & 1.0376 & 0.2205 & 1.071 & 1.088 & 0.2258 & 1.095 & 1.119 \\
0.2468 & 1.0327 & 1.0431 & 0.2925 & 1.086 & 1.106 & 0.2874 & 1.11 & 1.137 \\
0.3319 & 1.0385 & 1.051 & 0.3705 & 1.099 & 1.122 & 0.3625 & 1.123 & 1.153 \\
0.4269 & 1.043 & 1.0558 & 0.4325 & 1.105 & 1.131 & 0.4405 & 1.129 & 1.162 \\
0.4858 & 1.0441 & 1.0588 & 0.5124 & 1.106 & 1.133 & 0.5101 & 1.13 & 1.164 \\
0.5695 & 1.0435 & 1.0579 & 0.5825 & 1.1 & 1.128 & 0.5825 & 1.124 & 1.159 \\
0.6412 & 1.0409 & 1.054 & 0.6612 & 1.087 & 1.116 & 0.6635 & 1.111 & 1.147 \\
0.7082 & 1.0367 & 1.0483 & 0.7402 & 1.072 & 1.1 & 0.7321 & 1.096 & 1.131 \\
0.7729 & 1.0295 & 1.0384 & 0.8145 & 1.054 & 1.08 & 0.7956 & 1.078 & 1.111 \\
0.8415 & 1.0208 & 1.0268 & 0.8852 & 1.032 & 1.055 & 0.8612 & 1.056 & 1.086 \\
0.9069 & 1.0123 & 1.0156 & 0.9124 & 1.024 & 1.039 & 0.9212 & 1.034 & 1.06 \\
1 & 1 & 1 & 1 & 1 & 1 & 1 & 1 & 1 \\
\hline
\end{tabular}


Figures 1-3 represent the variation of $U_{\exp }^{2} / \mathrm{U}^{2}{ }_{\text {imix }}$ with mole fraction of ethyl aniline with all three studied binary systems. It is observed that in ethylaniline+toluene system it is maximum at approximately $0.48 \mathrm{M}$ and in the case of and ethyl aniline and $o$-nitro toluene + $\mathrm{m}$-nitro toluene systems it is minimum at approximately $0.51 \mathrm{M}$ at all the temperatures.
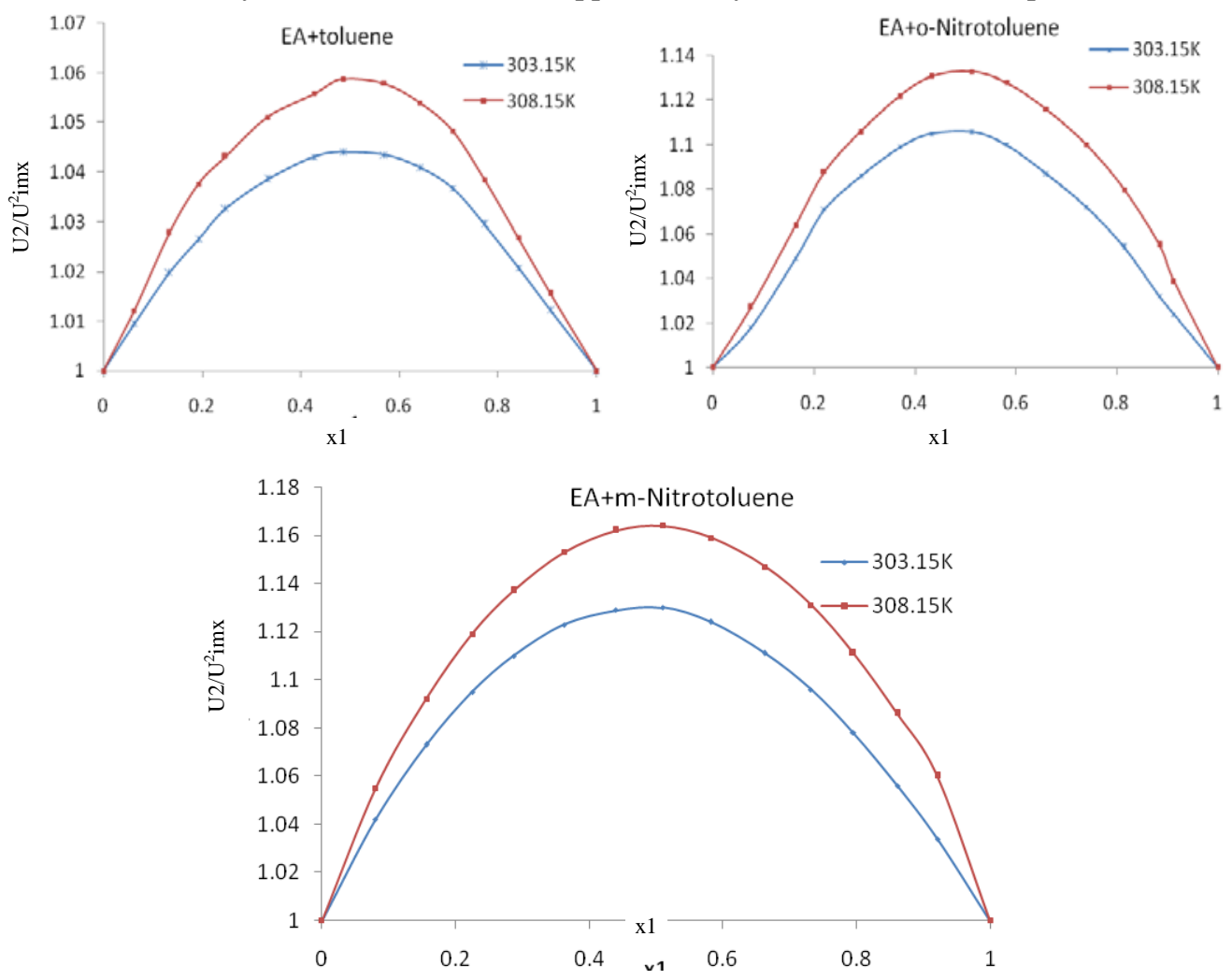

Figures 1-3. Plots of $\mathrm{U}^{2}{ }_{\text {exp }} / \mathrm{U}^{2}{ }_{\text {imix }}$ for the studied systems at temperatures $303.15 \mathrm{~K}$ and $308.15 \mathrm{~K}$

The interaction parameter characterizing a system varies with the composition, molar mass and temperature. It is employed to account for the contribution of non-combinatorial entropy of mixing and the enthalpy of mixing to the Gibb's energy of mixing. A positive value of $\alpha$ in all the system clearly indicates the existence of strong tendency for the formation of association in mixture through dipole-dipole interactions higher values of percentage deviation indicates maximum departure of the particular theory from experiment at that particular concentration. In systems studied, we observed that the interaction parameters are having a very low magnitude for all the given mixtures, indicating moderate/ weaker interactions, though hydrogen bonding, which decreases from $o$-nitro toluene to m-nitro toluene.

The deviations between theoretical and experimental value of ultrasonic velocities decrease with increase of temperature due to breaking of hetero and homo molecular clusters at higher temperatures ${ }^{27}$. On increasing the temperature, the ultrasonic velocity values decrease in the three binary liquid mixtures. This is probably may be due to the fact that the thermal energy activates the molecule, which would increase the rate of association of unlike molecules. 
On the whole, all the theoretical models fairly predicted ultrasonic velocities, are reasonably close to the experimental values for and the three binary mixtures reported in this work, thus showing the validity of studied theoretical models for binary mixtures. The predictive abilities of various ultrasonic theories discussed above, depend upon the strength interaction prevailing in a system ${ }^{28}$.

\section{Conclusion}

The application of various ultrasonic velocity theories have been studied with binary mixtures of $N$-ethyl aniline with toluene $o$-nitro toluene and $m$-nitrotoluene. It may be concluded that out of five theories and relations discussed above the Nomoto's relation, Van Deal ideal mixing relation and Impedance relation provided good results. Thus, the linearity of molar sound velocity and additivity of molar volumes, as suggested by NomotoVan Dael and Vangeel and Impedance relation, in deriving the empirical relations have been truly observed in the studied binary liquid mixtures.

\section{References}

1. Rama Rao G V, Viswanatha Sarma A, Sivarama Krishna J and Rambabu C, Indian J Pure Appl.Phys., 2005, 43(5), 345-354.

2. Vasantharani P, Muthu Shailaja S, Kannappan A K and Ezhil Pavai R, J Appl Sci., 2008, 8(12), 2329-2332.

3. Oswal S L, Pandiyan V, Krishnakumar B and Vasantharani P, Thermochim Acta, 2010, 507-508; DOI:10.1016/j.tca.2010.04.025

4. $\quad$ Pandey J D, Ranjan Dey and Dwivedi D K, Pramana J Phys., 1999, 52(2), 187.

5. $\quad$ Sumathi T and Umamaheswari J, Indian J Pure Appl Phys., 2009, 47, 782.

6. Bala Karuna Kumar D, Rayapa Reddy K, Srinivasa Rao G, Rama Rao G V and Rambabu C, Asian J Chem., 2012, 24(5), 2239-2244.

7. Ali A ,Yasmin A and Nain A K, Indian J Pure Appl Phys., 2002, 40, 315-322.

8. Rayapa Reddy K, Bala Karuna Kumar D, Rambabu C and Srinivasa Rao G, E-J Chem., 2012, 9(2), 553-562; DOI:10.1155/2012/571521

9. Ali A A, Nain A K and Soghra Hyder, J Pure Appl Ultrason., 2001, 23, 73.

10. Nomoto O, J Phys Soc Japan, 1949, 4, 280-283; DOI:10.1143/JPSJ.4.280; ibid. J Chem Phys., 1953, 21, 950; DOI:10.1063/1.1699084

11. Van Dael W and Vangeel E, Pro Int Conf on Calorimetry and Thermodynamics, Warsaw, 1955, 555.

12. Shipra Baluja and Parsania P H, Asian J Chem., 1955, 7(2), 417-423.

13. Rao R, J Chem Phys., 1941, 9, 682; DOI:10.1063/1.1750976

14. Junjie Z, J China Univ Sci Techn., 1984, 14, 298-300.

15. Langeman R T and Correy J E, J Chem Phys., 1942, 10(12), 759;

DOI:10.1063/1.1723659

16. Rendal G R, Proc Ind Acad Sci., 1942, 16A, 369.

17. Auslander D and Onitni L, Acustica., 1971,24, 205.

18. Samal K and Misra S C, J Phys Soc Japan., 1972, 32(6), 1615; DOI:10.1143/JPSJ.32.1615

19. Aziz R A, Bowman D H and Lim C C, Can J Phys., 1972, 50(7), 721-727; http://dx.doi.org/10.1139/p72-102

20. Poole G R and Aziz R A, ibid., 1972, 50, 646-654.

21. Younglove B A, J Acoust Soc Am., 1965, 38, 433; DOI:10.1121/1.1909707 
22. Nikam P S, Jagdale B S, Sawant A B and Mehdi Hasan, J Pure Appl Ultrason., 2000, 22, 115.

23. Ali A and Nain A K, J Pure Appl Ultrason., 2000, 22, 10.

24. Pal A and Singh Y P, J Chem Eng Data., 1995, 40, 818-822; DOI:10.1021/je00020a018

25. Reddick J A, Bungar W B and Sakano T, Organic solvents: Physical Properties and methods of purification, $4^{\text {th }}$ Edn. Wiley Interscience, New York, 1986.

26. Zareena Begum, Sandhya Sri P B and Rambabu C, ISRN Physical Chemistry Volume 2012, Article ID 943429, DOI:10.5402/2012/943429

27. Ali A, Nain A K, Vinod Kumar Sharma and Shakil Ahmed, Indian J Pure Appl Phys., 2004, 42, 666.

28. Jhansi Lakshmi B, Gowri Sankar M, Zareena Begum, Ramachandran D and Rambabu C, Elixir Ultrasonics., 2013, 65, 19808-19814. 